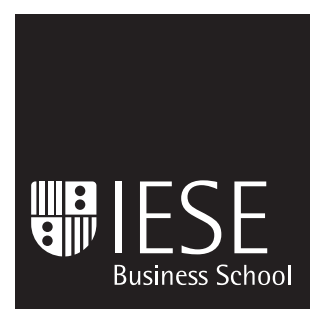

CIIF

Working Paper

WP no 734

University of Navarra

February, 2008

\title{
NON-LINEAR ADJUSTMENT OF IMPORT PRICES IN THE EUROPEAN UNION
}

\author{
José Manuel Campa \\ José M. González Mínguez \\ María Sebastiá Barriel
}


The CIIF, International Center for Financial Research, is an interdisciplinary center with an international outlook and a focus on teaching and research in finance. It was created at the beginning of 1992 to channel the financial research interests of a multidisciplinary group of professors at IESE Business School and has established itself as a nucleus of study within the School's activities.

Ten years on, our chief objectives remain the same:

- Find answers to the questions that confront the owners and managers of finance companies and the financial directors of all kinds of companies in the performance of their duties

- Develop new tools for financial management

- Study in depth the changes that occur in the market and their effects on the financial dimension of business activity

All of these activities are programmed and carried out with the support of our sponsoring companies. Apart from providing vital financial assistance, our sponsors also help to define the Center's research projects, ensuring their practical relevance.

The companies in question, to which we reiterate our thanks, are:

Aena, A.T. Kearney, Caja Madrid, Fundación Ramón Areces, Grupo Endesa, Royal Bank of Scotland and Unión Fenosa.

http://www.iese.edu/ciif/ 


\title{
NON-LINEAR ADJUSTMENT OF IMPORT PRICES IN THE EUROPEAN UNION
}

\author{
José Manuel Campa ${ }^{1}$ \\ José M. González Mínguez² \\ María Sebastiá Barriel ${ }^{3}$
}

\begin{abstract}
This paper focuses on the non-linear adjustment of import prices in national currency due to shocks in exchange rates and foreign prices, measured in the exporters' currency, of products originating outside the Euro area and imported into European Union countries (EU-15). The paper looks at three different types of non-linearities: (a) non-proportional adjustment (the size of the adjustment grows more than proportionally with the size of the misalignments), (b) asymmetric adjustment to cost-increasing and cost-decreasing shocks, and (c) the existence of thresholds in the size of misalignments below which no adjustment takes place. There is evidence of more than proportional adjustment towards long-run equilibrium in manufacturing industries. In these industries, the adjustment is faster the further current import prices are from their implied long-run equilibrium. In contrast, a proportional linear adjustment cannot be rejected for some other imports (especially within agricultural and commodity imports). There is also strong evidence of asymmetry in the adjustment to long-run equilibrium. Deviations from longrun equilibrium due to exchange rate appreciations of the home currency result in a faster adjustment than those caused by home currency depreciation. Finally, we also find that adjustment takes place in the industries in our sample only when deviations are above certain thresholds, and that these thresholds tend to be somewhat smaller for manufacturing industries than for commodities.
\end{abstract}

\footnotetext{
${ }^{1}$ Professor of Financial Management, Grupo Santander Chair in Financial Institutions, IESE

${ }^{2}$ Banco de España

${ }^{3}$ Bank of England
}

Clasificación JEL: F31, F36, F42

Keywords: exchange rate adjustment, European Union, monetary union. 


\section{NON-LINEAR ADJUSTMENT OF IMPORT PRICES IN THE EUROPEAN UNION}

\section{Summary}

The impact that movements in nominal exchange rates have on the geographical allocation of economic activity and the volume of trade has been at the core of research in international economics for over three decades. One key point in this debate is the degree, speed and form in which domestic prices of imported products adjust to exchange rate changes. It is often reported that the high volatility of nominal exchange rates is not matched by the behavior of import prices, which tend to be far less volatile. This gives rise to fluctuations in real exchange rates (the exchange rate adjusted for relative prices) which have been seen to be large and persistent over the past three decades, suggesting that the adjustment of import prices is very slow.

Several reasons have been suggested for such a slow adjustment of import prices. These include the existence of product differentiation and imperfect competition that can isolate, at least partially, foreign producers' pricing policies from exchange rate changes (implying price differentials between domestically-produced and imported, tradable products), and the presence of price rigidities driven by some form of fixed cost to changing prices.

Understanding the speed and the form in which import prices - and, thus, real exchange rates adjust to their long-run equilibrium is an important issue in order to comprehend and anticipate inflation developments and, consequently, to provide an appropriate policy response by monetary policy authorities.

The adjustment of import prices to nominal exchange rate changes has also been an important part of the economic policy debate within the European Union (EU). The adoption of the Euro by a subset of twelve countries, and the large fluctuations in the value of this currency relative to the US dollar, have led to a profound interest in the underlying determinants of import prices and their relationship with exchange rate and monetary conditions.

This paper looks at the process of adjustment of import prices in EU countries towards their long-run equilibrium, when the deviation is due to changes in exchange rates or foreign prices. The main purpose of the analysis is to gain a better understanding of this adjustment process, in particular by looking at the possibility of a non-linear relationship between deviations from, and adjustments to, the long-run equilibrium (i.e. there is not a simple proportional relationship between the two). It is possible that prices react proportionally less to small deviations from equilibrium than to large deviations, or that the speed of adjustment back to equilibrium differs 
when prices are above or below that equilibrium. This is in contrast to the usual assumption that prices adjust linearly; that is, in strict proportion to the size of the deviation. Looking for evidence of non-linearities should help gain a better understanding of this adjustment process. A secondary goal that we try to achieve in this paper is to compare import price adjustment patterns among EU members that have adopted the Euro as their currency and the non-Euro area countries. If they are different, this could give us some insight into a possible structural change when joining a monetary union, which would ultimately affect inflation.

As far as non-linear adjustments are concerned, we considered three different possibilities: that they increase with the size of the deviation (non-proportionality); that they are asymmetric with respect to the sign of the deviation and, finally, that certain thresholds in the size of the deviation exist, below which no adjustment takes place. We test these ideas by modeling the process driving foreign prices, nominal exchange rates and import prices in domestic currency, allowing for non-linear adjustments. We use a combination of techniques proposed in previous work to estimate such adjustments. We find strong evidence for the presence of non-linearities in the adjustment towards long-run equilibrium in certain industries: this effect is stronger in manufacturing industries, for instance. Non-proportional adjustment among manufactures points to the characteristically higher degree of price differentiation in these products as an explanation for less adjustment. In contrast, linearity cannot be rejected for agricultural and commodity imports. In some (manufacturing and non-manufacturing) industries, the adjustment is faster the further away current import prices are from their implied long-run equilibrium.

However, in manufacturing there is further evidence of asymmetry in the adjustment to longrun equilibrium: deviations from long-run equilibrium due to exchange rate appreciations of the home currency result in a faster adjustment than those caused by home currency depreciation. Finally, we also find evidence that prices do not adjust when the deviations are small. We estimate the minimum deviation required for prices to adjust and find that these thresholds tend to be much smaller for manufacturing industries than for commodities.

The resulting evidence points towards adjustment patterns that may differ by country. In general, the patterns of adjustment might be driven by the industry composition of each country's imports and by the competitive structure in each of those industries. In principle, it can be expected that the rate at which cost changes are 'passed through' into prices are lower and less linear in Euro area member states than in countries outside the EMU. The reason is that the possibilities for foreign producers to deviate from local producers' pricing policies seem to be less pervasive in larger import destinations. However, the evidence does not point in this direction. In contrast, non-Euro EU member countries do not appear to have significantly different adjustment patterns from Euro area member states. This suggests that there are no structural differences between these two sets of countries in pass-through rates, and that the introduction of the Euro, by non-Euro area member states, is not likely to cause a structural change in this relationship. 


\section{Introduction}

The impact that movements in nominal exchange rates have on the geographical allocation of economic activity, the volume of trade and the degree of domestic adjustment has been at the core of research in international economics over three decades. One key point in this debate is the degree, speed and form in which domestic prices of imported products adjust to exchange rate changes (or, more generally, to export prices denominated in the destination currency). The volatility of import prices expressed in the currency of the importer is mainly due to the behavior of nominal exchange rates, with foreign prices in the currency of the exporter contributing much less to such movements. However, it is often reported that the high volatility of nominal exchange rates is not matched by the behavior of import prices, which tend to be far less volatile. This gives rise to fluctuations in real exchange rates which have shown to be large and persistent over the past three decades, suggesting that the adjustment of import prices is very slow ${ }^{1}$.

Several reasons have been suggested in the literature for such a slow adjustment of import prices. Explanations include the presence of a significant local content component in the value added of imported products (Burstein et al., 2003), the existence of product differentiation and imperfect competition that lead to price differentials between domestically-produced and imported, tradable products, and the presence of price-rigidities driven by some form of fixed cost to changing prices ${ }^{2}$. In the case of aggregate prices, such as consumer prices, the adjustment is even slower, due to the presence of non-tradable products in the composition of such aggregate price indices and to the impact of macroeconomic stability on the pricing behavior of producers (Giovannini, 1988; Knetter, 1993).

More recently, the stability of exchange rate pass-through rates over time has been brought to the centre of macroeconomic debates. Taylor (2001) and Goldfajn and Werlang (2000), among others, have argued that the reported low pass-through rates may even have been declining over time. The issue posed in these and related studies is whether this decline in pass-through rates is due either to improved macroeconomic conditions in the importing countries or to some other economic changes. The recent Brazilian experience is often cited as an example of the lack of adjustment in import prices to exchange rate changes. Between December 1998 and October 2002, the exchange rate between the real and the US Dollar suffered a heavy depreciation, increasing by about 215\%, while import prices in domestic currency increased by only about $100 \%$, which seems to be, at first sight, a good example of reduced pass-through. However, it can be also interpreted in a somewhat slightly different way, as an example of slow, but unfinished, adjustment. Indeed, subsequently, the real/USD exchange rate partially reversed its earlier depreciation, reducing by 37\% until July 2005, while import unit values rose by 5\% in the same period. Taken over the whole period (December 1998 to July 2005), the increases in the exchange rate and in import prices were very similar (at 199\% and 208\%, respectively). So, the issue at stake would appear to be one of very slow adjustment rather than no adjustment at all.

\footnotetext{
${ }^{1}$ The literature on the stability of real exchange rates and the convergence to purchasing power parity is very large and has not reached a consensus on whether real exchange rates are stationary or not, and on what are the key determinants of this stationarity. See Rogoff (1996) and Obstfeld and Rogoff (2000) for excellent surveys.

${ }^{2}$ The theoretical work in this literature includes Froot and Klemperer (1989), Giovannini (1988) and Marston (1990). Goldberg and Knetter (1997) provide a review of this literature.
} 
The adjustment of import prices to real exchange rate changes has also been an important part of the economic policy debate within the European Union (EU). The adoption of the Euro by a subset of twelve countries and the large fluctuations in the value of this currency relative to the US Dollar, jointly with the discussion of the conditions for the introduction of the currency in other EU Member States, have led to a profound interest in the underlying determinants of import prices and their relationship with exchange rate and monetary conditions. The introduction of the Euro has suggested the possibility that Euro-area countries might be affected asymmetrically by exchange rate movements, which might result in the stance of the single monetary policy not being equally optimal for all countries in the face of an exchange rate shock. That asymmetric impact might be due to country-specific factors for a given industry or to industry-specific factors combined with different trade structures in each country. In a study restricted to Euro-area countries, Campa and González Mínguez (2006) estimated that exchange rate pass-through is incomplete in the short-run: import prices reflect on average about $60 \%$ of the changes in the exchange rate. Long-run pass-through is closer to one. The results also show that there exist wide differences among industries and countries on the degree of short-term exchange rate pass-through, while equality tends not to be rejected in the long run. Pass-through appears to be lower in manufacturing industries than in commodity industries. In a more recent study, Campa, Goldberg and González Mínguez (2005) check for the existence of a structural break since the introduction of the Euro and they do find that, although pass-through rates appear to have declined in Euro-area member countries since 1998, this effect was not statistically significant.

The purpose of this paper is to further address the issue of the adjustment of import prices to changes in exchange rates. In particular, we explore the short-run adjustment of the deviation of import prices from their long-run relationship with exchange rates and foreign prices by allowing this adjustment to be nonlinear. We explore three different types of nonlinear adjustment: non-proportional adjustment, asymmetric adjustment and the existence of thresholds below which the adjustment does not take place at all. Furthermore, we compare the adjustment between Euro-area countries and the rest of the EU-15 Member States. ${ }^{3}$

The observed evidence points to the existence of patterns of adjustment that are more homogeneous within an industry across countries, than for different industries in a given country. We find strong evidence of the presence of non-linearities in the adjustment towards long-run equilibrium in certain industries. A proportional adjustment cannot be rejected for some non-edible commodity imports while non-proportional adjustment is somewhat more prevalent in manufacturing industries and also for agricultural commodities. In these industries, the adjustment is faster the further away current import prices are from their implied long-run equilibrium. There is also evidence of asymmetry in the adjustment to the long-run equilibrium. Deviations from the long-run equilibrium due to real exchange rate appreciations of the currency of the destination country result in a faster adjustment than those caused by depreciation. This is consistent with the idea that foreign companies facing a depreciation of the currency of the destination market may choose to compress margins in order to avoid a loss of market share. Finally, we find evidence of the existence of thresholds below which adjustment does not take place. These thresholds appear to be somewhat smaller for manufacturing industries than for commodity industries.

\footnotetext{
${ }^{3}$ The unavailability of data on the 10 new Member States prevents us from extending the analysis to non-Euro area EU countries other than the three belonging to the old EU-15.
} 
The rest of the paper is organized as follows: The next section reviews in more detail the theoretical arguments behind non-linear adjustment. Section 3 describes the data set used in the empirical analysis. Section 4 briefly describes the methodology in a linear setting (as in Campa and González Mínguez, 2006), and presents some initial benchmark estimates assuming such a linear adjustment. Section 5 presents the non-linear methodology and the evidence on the existence of a relationship of that nature in the adjustment process of import prices for each of the three aforementioned types of non-linearities: non-proportionalities, asymmetries and thresholds. Section 6 brings together some conclusions and points towards areas for further work.

\section{Motivation}

Understanding the speed and the form in which import prices - and, thus, real exchange rates adjust to their long-run equilibrium takes place is an important issue in order to comprehend and anticipate inflation developments and, consequently, to provide an appropriate policy response by monetary policy authorities. To develop a deeper insight into the way this adjustment takes place we focus on the analysis of non-linear adjustments that may, in principle, be industry-specific. Let us define, for now, deviations in the real exchange rate in a given industry as deviations from the long-run relationship between import prices expressed in the currency of the importing country, producer prices in the currency of the foreign exporter, and the nominal exchange rate between both currencies. For any given trajectory of foreign prices and the nominal exchange rate, if import prices do not adjust immediately to fulfill this long-run relationship, disequilibrium in the real exchange rate will ensue.

There are a number of reasons for such an adjustment in import prices to be non-linear. First, there may be a threshold below which no adjustment takes place. To be more precise, at the level of the individual company, the degree of adjustment of import prices may vary with the size and the perceived persistence of the shock that sets the adjustment in motion. For instance, if the exchange rate is volatile, but with no clear trend, any individual exporting company will tend not to adjust prices in the currency of the destination country and exchange rate changes will normally be absorbed by temporary adjustments in margins. Fluctuations in exporting margins for small exchange rate movements will be most likely when there are adjustment costs to changes in import prices, such as menu costs. The size of these adjustment costs will act in practice as a minimum threshold below which deviations from the long-run import price will result in companies not adjusting their import prices. As the deviation becomes larger or more persistent in time, individual companies will start adjusting their prices in local currency. The existence of such thresholds, however, is unlikely to be easily identified when looking at aggregate import price data. This is because thresholds are likely to be specific to the industry or even to the company. When aggregating this behavior across industries, it is likely that the resulting process is smooth although driven by the existence of significant thresholds at the industry- or company-level. Here we evaluate the presence of thresholds at the industry level.

Second, the pace of the adjustment is likely to increase more than proportionally with the size of the deviation from the long-run equilibrium. The proportion of companies adjusting their import prices will be a function of the size of the deviation from the long-run relationship. As such deviations become larger, more and more importers will find it worthwhile to adjust their import prices rather than accepting the deviation from equilibrium prices to be absorbed by their margins. 
Third, it is possible that asymmetries exist in the degree and speed of adjustment of import prices to long-run deviations. Transmission of cost-increasing shocks (such as a depreciation of the importer's currency) implies increases in the local price of imports. The resulting changes in the competitive position of the imported product are likely to lead to losses in market share. Thus, under this type of shock, importers may choose to pass-through a smaller percentage of the exchange rate change into the import price so as to maintain their market share. This argument is particularly relevant if hysteresis effects are at play, so that a temporary loss in market share due to an increase in prices in the domestic currency is likely to become permanent (Froot and Klemperer, 1989).

More generally, the adjustment of import prices towards their long-run equilibrium relationship depends on the market structure and the pricing strategy of firms, which may differ by industry. Common explanations for incomplete pass-through rates rely on the existence of market structures which deviate from perfect competition. Market structure characteristics can also explain the existence of non-linearities in the adjustment of import prices to deviations from their long-run equilibrium. The degree of substitutability between domestic and foreign goods, and the degree of international integration in the industry, are factors which have been highlighted in literature as being able to affect the pattern of import price adjustment. ${ }^{4}$ Industries producing globally tradable and homogeneous products, such as commodity industries, should experience a larger degree of short-run adjustment and are less likely to exhibit non-linear adjustment. Industries in which products are more differentiated and/or its market structure is less competitive, such as differentiated manufacturing products, will be more likely to experience patterns of non-linear adjustment.

Our empirical approach to the issue is based on modeling changes in the real exchange rate via an error-correction mechanism with a nonlinear adjustment pattern towards long-run equilibrium. We follow recent work by Escribano (2004) and model the nonlinear adjustment process through a cubic polynomial function that allows for the possibility of intervals in which no adjustment takes place. We also use semi-parametric techniques based on spline functions to check the robustness of our results.

\section{Data for the Empirical Analysis}

We use unit value indices of imports into each EU-15 country as the proxy for import prices for a set of twelve product categories. Given that most of the deviations in the real exchange rate occur through movements in the nominal exchange rate, we focus, for the Euro-area countries, on imports coming from outside the Euro zone since this is the part of the total trade of these countries that continues to be exposed to exchange rate fluctuations after the creation of EMU in $1999^{5}$. For consistency, we use the same approach for the three EU-15 countries not taking part in $\mathrm{EMU}^{6}$. The database, which is described in more detail in the appendix, contains

\footnotetext{
${ }^{4}$ Under full competition between foreign and local producers, if local production is very intensive in foreign intermediate goods, a shock to the costs of the foreign producer in local currency (for instance, an appreciation of the currency of the foreign exporter) amounts to an industry-wide cost shock affecting both local and foreign producers. This could be true even under less-than-full competition.

${ }^{5}$ In principle, we could also have attempted to study the adjustment of the prices of, say, Belgian imports coming from the rest of the Euro area whenever the prices in the countries of origin change.

${ }^{6}$ Notice that this gives rise to some kind of asymmetric treatment since, while we are considering imports into the Euro area coming from the UK, the opposite is not true.
} 
monthly time series data for the period 1989 to 2004 on import unit values for different product categories for each destination country ${ }^{7}$.

The product disaggregation contains twelve different categories. In principle, we work at the one-digit level of disaggregation of the Standard International Trade Classification (SITC), which provides nine different product categories (coded from zero to eight). Higher levels of disaggregation imply, in principle, that the resulting industry groups contain more homogeneous products. However, working at a very high level of disaggregation also comes at a cost, since information for disaggregated categories is more prone to contain measurement errors. We solve this trade-off by further disaggregating only the manufacturing industries, SITC groups 7 (Transport and machinery) and 8 (Other manufacturing), which contain the lion's share of imports into three and two subcategories respectively ${ }^{8}$. We code these resulting five new subcategories as 7-1, 7-2, 7-3, 8-1 and 8-2. The resulting industry sample contains seven one-digit categories and five two-digit categories.

The respective shares of imports belonging to each product category within total imports vary widely. Electric and electronic machinery, Basic manufactures and Mineral fuels account for the largest portion of non-Euro area imports for most countries in the sample. Moreover, the shares of the various industries in overall non-Euro area imports show a large degree of heterogeneity with Portugal, Greece and Spain having, for instance, very large shares for imports of Mineral fuels, but relatively low shares in imports of Electric and electronic machinery.

Disaggregating imports into each country according to their composition by products makes it possible to account for different rates of pass-through among different product categories for any given country, and vice versa. This heterogeneity in the degree of industry and country import price adjustment is likely to be important ${ }^{9}$. However, this industry disaggregation also has important limitations. Mainly, we work with indices based on unit values rather than prices. These indices are unable to account for any differences in the product composition of a given industry across countries. They are also not adjusted for changes over time in the composition of the import bundle within each industry. These could imply deviations of the unit value index from the true price and poses issues of product comparability across countries, and of possible changes in product composition over time for a given industry and country ${ }^{10}$.

The other two relevant pieces of data are the nominal exchange rates and the marginal cost, or foreign price, proxy. Following the evidence from previous work (Campa and González Minguez, 2006) on the appropriate foreign benchmark, we use the U.S. Dollar price of the imports coming from outside the area as our proxy for the foreign price in each industry, and the bilateral exchange rate between the domestic currency and the U.S. Dollar as the measure of nominal exchange rates.

\footnotetext{
${ }^{7}$ In fact, due to data availability reasons, Belgium and Luxembourg are treated as a single country.

8 These five subcategories are: Heavy machinery, Electric and electronic equipment, Vehicles and transport equipment, Home equipment and clothing, and Precision equipment. See the data appendix for details regarding the data.

${ }^{9}$ In particular, it is interesting to explore whether exchange-rate pass-through is predominantly a country-specific or an industry-specific phenomenon. For instance, Campa and Goldberg (2005) find evidence of the latter of these two possibilities, i.e. markets for the different industries of a given country tend to be more different from each other than the markets for a given product in different countries.

${ }^{10}$ Also, since we use data which are aggregated with regard to the criterion of the country of origin of the imports, our data disregard possible changes in the relative weights of different countries of origin along time.
} 


\section{Methodological Approach and Empirical Estimates in a Linear Setting}

Import prices, the nominal exchange rate and foreign prices are assumed to satisfy the following long-run cointegration relationship:

$$
\ln M P_{t}^{i, j}=c_{1}^{i, j} \ln E R_{t}^{i, j}+c_{2}^{i, j} \ln F P_{t}^{i, j}
$$

where the superscripts indexed by $\mathrm{i}$ and $\mathrm{j}$ refer, respectively, to an importing country and to an industry. We denote as $M P_{t}^{i, j}$ the import unit value index denominated in local currency of industry j in country i. $E R_{t}^{i, j}$ is the nominal exchange rate for industry j of country i expressed in terms of units of domestic currency per unit of foreign currency. Finally, $F P_{t}^{i, j}$ stands for the price index of products of industry $j$ into country $i$ in the countries of origin of these imports and expressed in foreign currency.

We explore the existence of such a cointegrating relationship by performing panel cointegration tests. For each industry, we pool the available information for the fourteen countries in the sample into an industry panel and test the null hypothesis of no cointegration. Pedroni (1999) constructs seven tests for cointegration in heterogeneous panels with multiple regressors - four are based on pooling within dimensions ('panel tests', i.e., across industries and countries) and three are based on pooling between dimensions ('group statistics', i.e., across time). The panel tests pool the residuals across countries and test the hypothesis of cointegration assuming the unit root properties of the error are the same across countries. Therefore, the panel statistics are a joint hypothesis of cointegration and homogeneity of the error process. The group statistics are preferred as they allow for heterogeneity in the error process across countries.

Table 1 reports the standardized values for the seven tests for a specification that includes the variables in equation (1). For each industry, we reject in all cases the null hypothesis of no cointegration in the panel. This evidence supports our modeling approach in equation (1), namely that a long-run relationship between foreign prices, exchange rates and import prices exists in the data.

The micro-foundations of pricing in equation (1) imply that there is a constant target mark-up of the import price in domestic and foreign currency over the foreign-currency denominated marginal cost of production. To the extent that this mark-up is not correlated with changes in the exchange rate, we will expect the long run cointegrating vector to be $(1,1,1)$. Differences from one in the estimated long-run relationship between import prices and exchange rates imply that changes in mark-up are correlated with exchange rate changes. The structure in equation (1) permits exchange rate adjustments to depend on the structure of competition in the industry and be different from one. This is consistent with the large amount of literature explaining cross-sectional industrial differences with respect to exchange rate pass-through, as it has been exposited simply and eloquently in Dornbusch (1987) and Marston (1990), among others, and supported empirically by Knetter (1993) and Yang (1997).

Given the existence of this long-run relationship we estimate an error correction model of the following form

$$
\Delta \ln M P_{t}^{i, j}=f\left(Z_{t-1}, \gamma\right)+c_{4}^{i, j} \Delta \ln E R_{t}^{i, j}+c_{5}^{i, j} \Delta \ln F P_{t}^{i, j}+c_{6}^{i, j} \Delta \ln M P_{t-1}^{i, j}
$$

where $Z_{t-1}=\left(\ln M P_{t-1}^{i, j}-c_{1}^{i, j} \ln E R_{t-1}^{i, j}-c_{2}^{i, j} \ln F P_{t-1}^{i, j}\right)$ and $\gamma$ is a set of parameters to be estimated. 
Short-run adjustment of import prices to exchange rate changes is given by the estimated coefficients $c_{4}^{i, j}$, while long run coefficients are given by $c_{1}^{i, j}$, where we have included the superscripts in order to highlight that these coefficients can vary by industry $\mathrm{j}$ and importing country i. The function $f(., \gamma)$ describes the form of the adjustment of short-term deviations of import prices towards their long-run equilibrium.

In the case in which $\mathrm{f}$ is a linear function of $\mathrm{z}$, we will use a linear specification as a benchmark for the adjustment. For alternative specifications of the function $\mathrm{f}$, we will have different forms of non-linear adjustment that we will estimate.

Thus, we start by estimating the linear error correction model. Before performing the estimation we impose additional constraints in the model in equation (2). Campa and González Mínguez (2006) find evidence supporting the idea that long-run pass-through rates differ across countries in the short run but not in the long run. Building on that result, we impose on equation (2) the additional restriction that $c_{1}^{i, j}=c_{1}^{j}$, i.e., long-run pass-through in an industry does not differ by country.

The estimates for this linear adjustment are reported in Table 2. Short-run adjustment is incomplete for the vast majority of industries and countries. Estimated short-run pass-through rates are different from zero in over $90 \%$ of the cases and are also different from one in the vast majority of combinations of industry and country. Given an industry, the equality of short-run adjustment rates can be rejected in almost all instances for the Euro-area member countries, with the exception of industry 8-2. For the three non-Euro area member countries, the equality of short-run elasticities is only rejected in four industries at the $10 \%$ level. This lower level of rejection for these countries is likely to be due to the smaller number of degrees of freedom, given that there are only three countries in this category.

Long-run adjustment rates to the exchange rate are higher than short-run rates. However, for the pool of the Euro-area member countries a long-run pass-through equal to one can be rejected for all but one of the twelve industries, indicating incomplete adjustment also in the long-run. We observe long-run adjustment rates significantly bigger than one in two instances, which is harder to justify. Long-run exchange rate adjustment rates for the group of non-Euro area member countries follow a similar pattern, with point estimates that are also substantially larger than the average short-term adjustment rates for all industries. For these countries, the hypothesis that the long-run pass-through rates are not different from one can only be rejected for six of the twelve industries, and there are no instances of statistically significant long-run adjustments bigger than one. Finally, higher pass-through rates into import prices should be expected for EU Member States not belonging to the Euro area than for Euro-area member countries, since foreign exporters are more likely to follow a pricing-to-market behavior, i.e., to maintain import prices constant in the importer's currency, with respect to a larger destination market. However, we only find weak evidence of this: point estimates are higher for non-Euro area countries for seven out of the twelve industries, while equality cannot be rejected in four cases. Both for Euro-area and non-Euro area countries, long-run adjustment rates to foreign prices are also reported. Adjustment to foreign prices is lower, on average, than to exchange rates. A long-run adjustment rate equal to one can be rejected for the large majority of industries. We checked the robustness of the estimation by re-estimating equation (2) restricting the long-term adjustment rates for all industries in a country to be the same. The resulting evidence is qualitatively and quantitatively similar to that obtained by restricting long-term 
adjustment within industries. There is evidence of partial adjustment both in the short run and long run, with coefficients in the long run being larger (Table 3$)^{11}$.

Finally, we test for the existence of non-linear adjustment using the RESET test. Ramsey's RESET tests use the squared fitted values obtained from the linear regression as an additional regressor in a second-stage regression. The null hypothesis that the correct specification is linear is rejected whenever the coefficient on the squared fitted values is found to be different from zero. The hypothesis of linearity is rejected in a very large majority of cases. ${ }^{12}$

\section{Non Linear Adjustment in the Exchange Rate Pass-Through}

Given the evidence on linear adjustment presented in the previous section, we now focus on the possibility of a non-linear adjustment. We explore three possible types of non-linearities. First, the adjustment may be non-proportional to the size of the deviation (let us name this kind of non-linearity "Type I"). Second, it may be non-symmetrical with respect to the sign of the deviation ("Type II"). And third, there may be a threshold in the size of the deviation below which no adjustment takes place (“Type III”).

We use a non-linear error correction model. These models allow for non-linear adjustments to short-run deviations by modeling the function $f\left(Z_{t-1}, \gamma\right)$ in equation (2) in a more flexible manner than the linear specification. Many alternative approaches have been suggested in literature for the estimation of $f\left(Z_{t-1}, \gamma\right)$. These alternatives include an exponential function (Dijk et al, 2002), a logistic function (Dijk et al, 2002), a flexible polynomial function (Escribano, 2004) or the use of semi-parametric methods such as cubic splines (Escribano, 2004). The exponential and logistic functions often present problems with identification in the estimation process ${ }^{13}$. Given the difficulties of dealing with this problem in view of the large number of estimated equations (as a result of the large dataset in terms of industries and countries), we pursued two more robust approaches. First, we use a parametric cubic polynomial function for the estimation of the short-run adjustment process to assess possible non-linearities in the response to exchange rate and foreign costs movements of different sign and size (Type I and Type II nonlinearities). Second, the approach is generalized to include thresholds (Type III).

Under the first approach, the cubic polynomial function we estimate takes the form

$$
f\left(\hat{z}_{t-1}, \gamma\right)=\gamma_{0}+\gamma_{1} \hat{z}_{t-1}+\gamma_{2} \hat{z}_{t-1}^{2}+\gamma_{3} \hat{z}_{t-1}^{3}
$$

\footnotetext{
${ }^{11}$ Another issue of interest is the stability of the estimated pass-through coefficients in this linear setting over time and, in particular, whether the introduction of the Euro implied a structural break in this relationship. Campa, Goldberg and González Mínguez (2005) find little evidence (concentrated particularly among manufacturing products) of the existence of a change in the rate of import price adjustment for Euro area countries after the creation of the Euro. Their findings report small evidence that for manufacturing products pass-through rates may have diverged after the creation of the Euro.

${ }^{12}$ More precisely, for the models reported in Table 2, the linear specification cannot be rejected, at 95\% significance level, in only 23 out of 154 cases. Interestingly, non-rejections tend to concentrate in some groups of products (5 for industry 1 and 4 for industries 7-3 and 8-1) and in some countries (for 7 Austrian industries and 4 in both Finnish and Swedish industries). For these three countries, the sample size is six years shorter than for the rest of countries, considerably reducing the power of the tests.

${ }^{13}$ It was also attempted to estimate an exponential function of the form $\mathrm{f}\left(\mathrm{z}_{\mathrm{t}-1}, \lambda\right)=1-\exp \left[-\lambda^{*} \mathrm{z}_{\mathrm{t}-1}{ }^{\wedge} 2\right]$. However, given the problems encountered in identifying the parameters for a large number of countries and industries, we decided to pursue the cubic polynomial approach.
} 
We perform the estimation of equations (2) and (3) in two-stages. First we estimate equation (2) under a linear adjustment process and obtain the values of $\hat{z}_{t-1}$ from the estimated parameters $\hat{c}_{1}$ and $\hat{c}_{2}$. Second, taking $\hat{z}_{t-1}$ as given, we estimate equation (3). Note that for simplicity be have dropped the industry and country superscripts from the coefficients in equation (3) and onwards.

Under this framework, the null hypothesis of a linear proportional adjustment (no Type I nonlinearity), can be tested through a joint test of the hypotheses that $\hat{\gamma}_{2}=\hat{\gamma}_{3}=0$. The joint rejection of these null hypotheses, plus the additional hypothesis that $\hat{\gamma}_{2}=0$, implies that the adjustment is also not symmetric (Type II nonlinearity).

An important shortcoming of this approach is its inability to identify the existence of an interval of small deviations from the long-run equilibrium for which there is no adjustment in the short-run. The existence of thresholds has been detected in previous studies looking at exchange rate adjustment to purchasing power parity (Obstfeld and Rogoff, 2000) and also in the literature of monetary policy adjustment (Escribano, 2004).

Thus, in our second approach, we search for the possible existence of an interval within which no adjustment to short-term deviations takes place (giving rise to Type III nonlinearity). We use the two-stage procedure suggested by Escribano (2004). First, a semi-parametric method based on smoothing cubic splines is employed in order to identify the interval in which the adjustment may not occur, since we need to identify ex-ante the range of values of $\hat{z}_{t-1}$ for which the adjustment appears to be zero. Then we fit a cubic polynomial to the space outside that interval to identify the nonlinear adjustment process. ${ }^{14}$

Spline smoothing is a very flexible estimation technique that has been widely used in finance and economics literature to fit nonlinear functions in a variety of different contexts such as macroeconomic variables (Granger et al., 1984; Engle et al., 1986), the modeling of non-linear investment decisions (Eberly and Abel, 1996), and the pricing of derivative instruments (Campa et al., 1998).

The smoothing spline is a piece-wise cubic polynomial ${ }^{15}$. For the spline, the points on the $x-$ axis corresponding to each observation of $\hat{z}_{t-1}$ define the "knot points". Between the knots the function is a simple cubic polynomial; however, the function is constrained so that it is continuous at the knots and has continuous first and second derivatives. To avoid over-fitting the data we also impose a smoothing penalty.

The procedure minimizes the following loss function:

$$
\operatorname{Min}\left((1-\lambda) \varepsilon_{z}^{\prime} \varepsilon_{z}+\lambda \delta^{\prime} V^{\prime} V \delta\right)
$$

where $\varepsilon_{z}=\Delta \ln M P_{t}^{i j}-f\left(z_{t-1}, \delta_{0}\right)-\delta_{1} \Delta \ln E R_{t}^{i j}-\delta_{2} \Delta \ln F P_{t}^{i j}-\delta_{3} \Delta \ln M P_{t-1}^{i j}, \delta$ is a set of parameters that includes the parameters from the cubic splines at point $\left(\delta_{0}\right), \delta^{\prime} V^{\prime} V \delta$ is a measure of the degree of curvature in the function -the integral of the squared second

\footnotetext{
14 One option would be to take the estimation in equation (3) as valid. Based on the estimated coefficients from that equation, one could estimate the size of the interval around zero in the nonlinear specification for which the hypothesis of zero adjustment cannot be rejected. This relies on the specification of equation (3) being the correct form of the non-linear adjustment function. Instead of this we use the semiparametric approach explained in the text that allows for additional flexibility.

${ }^{15}$ See de Boor (1978) for further details on splines.
} 
derivative of the function over its range-, and $\lambda$ and $1-\lambda$ are the weights assigned to each of the two terms in the loss function. The first component in this objective function is the sum of squared errors while the second term represents the smoothing penalty. It is standard when using smoothing splines to impose penalties based on the second derivative of the $f(.,$.$) function$ with respect to $\mathrm{z}_{\mathrm{t}-1}$, so as to minimize the differences in the size of this derivative at the end points of all adjacent intervals. The parameter $\lambda$ determines the degree of smoothness in the estimated function: the higher the value of $\lambda$, the higher the premium on a smooth function. We fix $\lambda$ to be 0.9998 .

Once we have estimated the smooth cubic spline for every combination of industry and country, we identify the interval of deviations from the long-run equilibrium for which the adjustment in import prices cannot be rejected to be zero, i.e., for which the system appears to be in long-run equilibrium. Then we estimate the degree of adjustment to short-term deviations by using a function that allows for the lack of adjustment within this interval of the following form:

$$
f\left(z_{t-1}, \phi\right)=\phi z_{t-1}\left(z_{t-1}-z^{-}\right)\left(z_{t-1}-z^{+}\right)
$$

This function has the advantage of allowing for an adjustment which is very close to zero along the interval $\left[\mathrm{z}^{-}, \mathrm{z}^{+}\right]$while requiring only one parameter to be estimated.

\section{Estimation Results}

Table 4 reports the results from estimating non-linear adjustment described by the cubic polynomials. The table reports the coefficient estimates for the parameters in equation (3), except $\gamma_{0}$. This equation has been estimated using the fitted values implied from the estimation of equation (1) as deviations, holding the long-run adjustment constant either for countries given an industry or from industries given a country. The left-hand panel in Table 4 reports the results from the estimation holding the parameters constant for the same industry across countries. The first three columns in the panel report the estimated parameters and their significance, while the last two columns show the results of testing for non-linearities. The last column refers to the test of the hypothesis that the adjustment is proportional (non-linearity of Type I), while the second to last column reports the results of a test of symmetry in the adjustment process (non-linearity of Type II).

\subsection{Type I Non-Linearity: Non-Proportional Adjustment}

The results show significant evidence of nonlinear adjustment in the data. The null hypothesis of linear adjustment can be rejected in three out of the seven one-digit industries in the sample. For industries 2 to 4 (Crude materials, Mineral fuels and lubricants and Animal and vegetable oils) the linear adjustment is not rejected. These industries are characterized by producing homogeneous products which are traded in largely integrated global markets, for which a world price for the product is, in general, well defined. A linear adjustment can only be rejected in one out of the five two-digit industries.

The right-hand panel of Table 4 reports similar results pooling the estimation for all industries within a country. Again, we find significant evidence for a nonlinear adjustment in passthrough rates. A linear adjustment cannot be rejected for all three non-Euro area Member States 
(United Kingdom, Denmark and Sweden) and also for the Netherlands, Austria, Italy and Greece. $^{16}$

We performed hypotheses tests on the equality of this nonlinear adjustment for the same industry (country) across the different countries (industries) in the sample. The results clearly indicate that the adjustment process is not only nonlinear, but also country- and industryspecific. We rejected the hypothesis of a pass-through that was not industry (country) specific in 37 (40) out of 126 possible cases.

Figure 1 reports, for each industry, the data plots of deviations against the actual changes in import prices, together with the shape of the nonlinear adjustment predicted by the estimates reported in Table 4 and the 95\% confidence intervals. The middle line shows the predicted short-run change in the import price in domestic currency (vertical axis) for a given short-term deviation from the long-run equilibrium path (horizontal axis). Given the differences in the range of fluctuations from the long-run equilibrium in Greece and Ireland relative to the other countries, we report the result estimates for all countries pooled, excluding these two.

A number of conclusions can be drawn. First, there is a range around zero for which the null hypothesis of lack of adjustment cannot be rejected. The confidence intervals can be quite wide and tend to be much wider for primary industries such as Fuels, Crude materials and Beverages and tobacco. The range of dispersion in the adjustment varies a lot across industries. Second, the adjustment is clearly nonlinear for many industries. All the charts show the same pattern of adjustment, with the adjustment being larger as the deviations from the long-run equilibrium increase. Linearity is harder to reject in those industries for which the range of variation in the data is larger.

Figure 1 also reports the analogous charts for the estimation by countries. These charts concompany the existence of non-linear adjustment and the existence of a threshold in the size of the deviation below which there is no adjustment. Results obtained in the case of Sweden are difficult to explain, since the adjustment (although non-linear) takes the opposite sign to that expected. However, the plot shows that the relation is close to linear, with a few observations having a disproportionate impact.

\subsection{Type II Non-Linearity: Asymmetric Adjustment}

The adjustment does not appear to be symmetric for appreciations and for depreciations relative to the long-run equilibrium. The second-to-last column in both panels of Table 4 reports the pvalues on the hypothesis of symmetric adjustment. Symmetric adjustment can be rejected for industries $0,5,6,7-1$ and 8-1; while it cannot be rejected for primary industries with homogeneous products such as Crude materials, Fuels and lubricants, and Animal and vegetable oils and for a number of manufacturing industries.

We checked for the importance of asymmetries in the estimated adjustment process of import prices by looking at the predicted adjustments from the model for deviations from the long-run equilibrium of given size 5\%,10\% and 25\%, both positive and negative. We observe in the data that about $60 \%$ of all short-term deviations are within the $[-0.1,0.1]$ range, so that the

\footnotetext{
${ }^{16}$ However, it may be interesting to note that this group of countries includes: (a) those which did not join the Euro, (b) Austria, which was a latecomer in the Exchange Rate Mechanism of the European Monetary System, and (c) Italy and Greece, characterised by low monetary stability prior to the introduction of the Euro.
} 
estimated predictions for deviations of a 5\% or 10\% size in absolute value correspond to the most relevant range in the data, while the $25 \%$ deviation corresponds to outlier values. Table 5 reports the short-term adjustment predicted for these deviations of the imported price in home currency from the long-run equilibrium relationship. The columns where this deviation is positive (negative) indicate that the current import price is above (below) the price implied by the long-run relationship and report the absolute size of the monthly adjustment in that deviation. In this table, we have indicated in bold those industries and countries for which the hypothesis of symmetry could not be rejected. Also, since a positive (negative) deviation is associated with an appreciation (depreciation) of the exchange rate, if the size of the adjustment is larger for positive (negative) deviations, this is shown in the table as DE $>$ AP (AP $>D E)$.

There is a clear pattern in the direction of the asymmetry in the short-run adjustment process. For all manufacturing industries for which symmetry could be rejected, we find that the shortterm adjustment is larger when the deviations from long-run equilibrium are positive ${ }^{17}$. The size of the asymmetry is also substantial. The median adjustment of a 25\% deviation in either direction is $9 \%$, while the median size of the asymmetry, measured as the difference to the adjustments to a positive versus a negative deviation, is 6\%. Import prices converge faster to the long-run equilibrium when they are above their equilibrium levels than when they are below. Since we can also interpret $\hat{z}_{t-1}$ being positive as a result of an exchange rate appreciation of the destination currency, deviations from long-run equilibrium due to exchange rate appreciations of the importing country currencies result in a faster adjustment than those caused by a depreciation. A depreciation of the destination currency implies a slower passthrough by foreign companies, probably in an attempt to maintain home currency import prices so as not to lose market share.

In contrast, there is no clear pattern when we compare asymmetry in the adjustment across the different countries. We find the adjustment to be slower (and statistically significant) for positive deviations from the long-run equilibrium for Belgium, Italy and Portugal, while for the other six countries for which the asymmetry is significant, the adjustment is faster in the case of a positive deviation. However, the size of the asymmetries is substantial for any given country. For instance, for a deviation from long-run equilibrium of $10 \%$, the median absolute difference in the size of the adjustment between a positive versus a negative deviation is $1 \%$, which equals $30 \%$ of the median adjustment.

\subsection{Type III Non-Linearity: Thresholds}

We also pursue the exploration of the thresholds that may exist around zero, inside of which adjustment towards the long-run equilibrium may not take place. We do this by applying the semi-parametric cubic spline methodology highlighted above, exploring any possible differences across countries and industries. We apply this method in two steps. First, we estimate a country- and industry-specific threshold interval; later, given these thresholds, we estimate the nonlinear adjustment implied by equation (5).

We estimate the threshold values for each interval by first estimating equations (2) and (4) allowing for the parameters in $\delta_{0}$ to vary by industry and country, i.e., $\delta_{0}^{i j}$. We then calculate the estimated semi-parametric nonlinear adjustment process and its standard errors over a

\footnotetext{
${ }^{17}$ Among manufacturing industries, point estimates are larger when deviations are positive in those instances for which symmetry cannot be rejected (industries 7-2 and 7-3). Symmetry can never be rejected in non-manufacturing industries with the exception of Food and live animals, for which the adjustment is larger under negative deviations.
} 
range of $\mathrm{z}$ values. The threshold values $\left(z^{-}, z^{+}\right)$are then defined as those values of $\mathrm{z}$ for each industry/country for which the null hypothesis of no adjustment can be rejected (i.e., lie outside the 95\% confidence interval) and result in the interval of the smallest size. Figure 2 contains, as an illustration, the case of industry 7-1 for Belgium.

The estimated values of $\left(z^{-}, z^{+}\right)$are reported in Figure 3, for the specification of equation (2) that estimated the long-run equilibrium to be common for every industry across countries. Estimated thresholds for most industries and countries are relatively small and within the range $[-0.1,0.1]$. As stated above, about $40 \%$ of the observations of $\mathrm{z}$ in the sample are outside of this range indicating that, at least for nearly half of all short-term deviations observed in the sample, short-run pass-through is significantly different from zero.

Estimated thresholds are considerably wider for certain countries such as Greece and Ireland. These countries also experienced larger exchange rate movements during the sample period. However, the estimation of their adjustment process is also noisier. For Greece, we even find that $z^{-}>z^{+}$in three industries. We lean towards interpreting these results as reflecting a lack of estimation precision due to high standard errors rather than as wider ranges for which exchange rate adjustment does not take place.

Threshold intervals tend to include zero, and very often are centered on it. There are very few instances for which the estimated thresholds do not include zero. Although thresholds vary by industry and country, some patterns arise. We find somewhat larger intervals for industries producing relatively homogeneous goods, such as Mineral fuels and Animal and vegetable oils and fats, although differences are relatively small.

We next estimate the nonlinear adjustment in the short-run taking into account the existence of these thresholds of no adjustment using the specification in equation (5). The results are reported in Table 6. As in Table 4, we report in the left-hand panel the coefficients from the pooled estimation across countries and, in the right-hand panel, the coefficient from the pooled estimation across industries. We do find that short-run adjustment outside the thresholds takes place in all industries, at the one and two-digit level, except in Animal and vegetable oils, in which adjustment does not happen even outside the interval defined by the thresholds. The estimated adjustment is significantly larger in the primary commodities industries, Food and live animals and Crude materials, than in the manufacturing industries. As was stated before, raw material industries also have in general larger thresholds in absolute value. Taken together, this evidence reflects that, although these industries do not adjust to small deviations, once these deviations are above the thresholds the adjustment happens quickly. We reject the equality in the adjustment process for different countries within an industry in all cases. The existence of adjustment beyond the estimated thresholds is less obvious when looking at the individual countries. We do not find evidence of adjustment for five countries in the sample: United Kingdom, Italy, Netherlands, Spain and Portugal.

\section{Conclusions}

This paper looks at the process of adjustment of import prices in EU countries towards their long-run equilibrium when they deviate from it due to changes in exchange rates or in foreign prices. The main purpose of the analysis has been to better understand this adjustment process, in particular by looking at the possibility of non-linearities in the adjustment process. A secondary goal that we try to achieve in this paper is to compare import price adjustment 
patterns between EU members that have adopted the Euro as their currency and the non-Euro area countries. As far as non-linear adjustments are concerned, we considered three different possibilities: that they increase with the size of the deviation (non-proportionality), that they are asymmetric on the sign of the deviation and, finally, that certain thresholds in the size of the deviation exist below which no adjustment takes place. We perform these tests by modeling the process driving foreign prices, nominal exchange rates and import prices in domestic currency via an error-correction model with a nonlinear adjustment. We use a combination of parametric and semi-parametric techniques that have been proposed in literature to estimate such an adjustment.

We take the linear adjustment case as a benchmark. For this specification, our results show that there is no systematic sign in the differential between the rates of adjustment of import prices toward their long-run equilibrium in Euro-area countries as compared to non-Euro area EU Member States.

We find strong evidence for the presence of nonlinearities in the adjustment towards long-run equilibrium in certain industries. This effect is stronger in manufacturing industries. Nonproportional adjustment among manufactures points to the higher degree of price differentiation that characterizes these products as an explanation for less adjustment. In contrast, linearity cannot be rejected for agricultural and commodity imports. In some (manufacturing and non-manufacturing) industries, the adjustment is faster the further current import prices are from their implied long-run equilibrium. However, in manufacturing there is greater evidence of asymmetry in the adjustment to long-run equilibrium: deviations from long-run equilibrium due to exchange rate appreciations of the home currency result in a faster adjustment than those caused by a home currency depreciation.

Finally, we also find evidence for the existence of thresholds of non-adjustment centered on zero. These thresholds tend to be much smaller for manufacturing industries than for commodities. The non-linear adjustment outside these estimated thresholds appears significant in all but one out of twelve industries. For some industries such as Animal and vegetable oils and fats or Crude materials the existence of these large thresholds could have been distorting previous tests of non-linearities.

The resulting evidence points towards adjustment patterns that may differ in the aggregate by country. In general, the patterns of adjustment might be driven by the industry composition of each country's imports and by the competitive structure in each of those industries. In principle, it could have been expected that pass-through rates were higher and more linear in Euro-area Member States than in countries outside EMU, given that the possibilities of pricing to market behavior seem to be more pervasive in larger import destination economic areas. The evidence does not point in this direction, though. On the contrary, non-Euro EU member countries do not appear to have significantly different adjustment patterns from Euro-area Member States. This suggests that there are no structural differences among these two sets of countries in passthrough rates and that the introduction of the Euro, by non-Euro area Member States, is not likely to cause a structural change in this relationship. 


\section{Data Appendix:}

Import Prices. Source: COMEXT (Eurostat). The data are monthly unit value indices of imports from non-Euro area countries of twelve product categories for fourteen countries (Austria, Belgium-Luxembourg, Finland, France, Germany, Greece, Ireland, Italy, Netherlands, Portugal, Spain, United Kingdom, Denmark and Sweden) from 1989:1 to 2004:6. The data is not seasonally adjusted. For Austria, Finland and Sweden the series start in 1995. We have used products at the 1-digit SITC level, with the exception of the product categories 7 (Machinery and transport equipment) and 8 (Other manufactures), which we have disaggregated into three and two subcategories, respectively, given their overall importance in total imports. The list of products is:

$\begin{array}{cll}\begin{array}{c}\text { Our code in } \\ \text { the tables }\end{array} & \text { SITC } & \text { Product Category } \\ 0 & 0 & \text { Food and live animals chiefly for food } \\ 1 & 1 & \text { Beverages and tobacco } \\ 2 & 2 & \text { Crude materials, inedible, except fuels } \\ 3 & 3 & \text { Mineral fuels, lubricants \& related materials } \\ 4 & 4 & \text { Animal and vegetable oils, fats and waxes } \\ 5 & 5 & \text { Chemicals and related products, n.e.s. } \\ 6 & 6 & \text { Manufactured goods classified chiefly by materials } \\ 7-1 & 71 \text { to } 74 & \text { Heavy machinery } \\ 7-2 & 75 \text { to } 77 & \text { Electric and electronic equipment } \\ 7-3 & 78 \text { and } 79 & \text { Vehicles and transport equipment } \\ 8-1 & 81 \text { to } 85 \text { and } 89 & \text { Home equipment and clothing } \\ 8-2 & 87 \text { and } 88 & \text { Precision equipment }\end{array}$

Exchange Rates. Source: DataStream.

Foreign Price Index. Source: COMEXT (Eurostat).The data are monthly unit value indices of imports from non-Euro area countries of the twelve product categories described above into the Euro area. 


\section{References:}

Burstein, Ariel, Joâo Neves, and Sergio Rebelo (2003), "Distribution Costs and Real Exchange Rate Dynamics during Exchange Rate Based Stabilizations.” Journal of Monetary Economics, 50 (6), pp. 1189-1214.

Campa, José, P.H. Kevin Chang, and James Reider (1998), "Implied Exchange Rate Distributions: Evidence from OTC Option Markets," Journal of International Money and Finance, 17(1), pp. 117-160.

Campa, José, and Linda Goldberg (2005), "Exchange Rate Pass-Through: A Macro or Micro Phenomenon?," The Review of Economics and Statistics, November.

Campa, José, and José M. González Mínguez (2006), “Differences in exchange rate pass-through in the Euro area," European Economic Review, 50 (1), pp. 121-141.

Campa, José, Linda Goldberg, and Josée M. González Mínguez (2005), "Exchange rate passthrough to import prices in the Euro area," National Bureau of Economic Research working paper no. 11632, forthcoming in Anderton, R. and Filippo di Mauro (eds.), "The External Dimension of the Euro area," Cambridge University Press.

De Boor, C. (1978), “A Practical Guide to Splines,” Springer-Verlag.

Dijk, Dick van, Timo Teräsvirta, and Philip Hans Franses (2002), "Smooth Transition Autoregressive Models - A Survey of Recent Developments," Econometric Reviews, 21(1), pp. 1-47.

Dornbusch, Rudiger (1987), "Exchange Rates and Prices," American Economic Review, 77(1), pp. 93-106.

Eberly, Janice, and Andrew Abel (1996), “Optimal Investment with Costly Reversibility,” Review of Economic Studies, August.

Engle, Robert, C.W.J. Granger, J. Rice, and A. Weiss (1986), "Semi-parametric estimates of the relation between weather and electricity demand," Journal of American Statistical Association 81: pp. 310-320.

Escribano, A. (2004), "Nonlinear Error Correction: The Case of Money Demand in the UK (18782000)," Macroeconomic Dynamics, 8 (1).

Froot, Kenneth, and Paul Klemperer (1989), "Exchange Rate Pass-through when Market Share Matters," American Economic Review, 79 (4), pp. 637-654.

Giovannini, Alberto (1988), "Exchange Rates and Traded Goods Prices," Journal of International Economics, 24, (1-2), pp. 45-68.

Goldberg, Pinelopi and Michael Knetter (1997), "Goods Prices and Exchange Rates: What Have we Learned?,” Journal of Economic Literature, vol. 35, pp. 1243-1292.

Goldfajn, Ilan, and Sergio Werlang (2000), "The Pass-through from Depreciation to Inflation: A Panel Study," PUC-RIO, Department of Economics, Working Paper n. 423.

Granger, C.W.J., F.C. Huynh, A. Escribano, and C. Mustafa (1984), "Computer investigation of some nonlinear time series models," In Proceedings of the Conference on Interface between Statistics and Computing.

18 - IESE Business School-University of Navarra 
Knetter, Michael (1993) “International Comparisons of Pricing-to-Market Behavior," American Economic Review, 83, pp. 473-486.

Marston, Richard (1990), "Pricing to market in Japanese manufacturing," Journal of International Economics, November.

Obstfeld, Maurice, and Kenneth Rogoff (2000), "New directions for stochastic open economy models,” Journal of International Economics, 50, pp. 117-153.

Pedroni, P. (1999), "Critical values for Cointegration Tests in heterogeneous Panels with Multiple Regressors," Oxford Bulletin of Economics and Statistics: Special Issue, pp. 653670.

Rogoff, Kenneth (1996), “The Purchasing Power Puzzle," Journal of Economic Literature, 34, June, pp. 647-668.

Taylor, John B. (2001), "Low Inflation, Pass-Through, and the Pricing Power of Firms," European Economic Review, vol. 44, issue 7, pp. 1389-1408.

Yang, Jiawen (1997), “Exchange Rate Pass-Through into U.S. Manufacturing Industries,” Review of Economics and Statistics. vol. 79, pp. 95-104. 

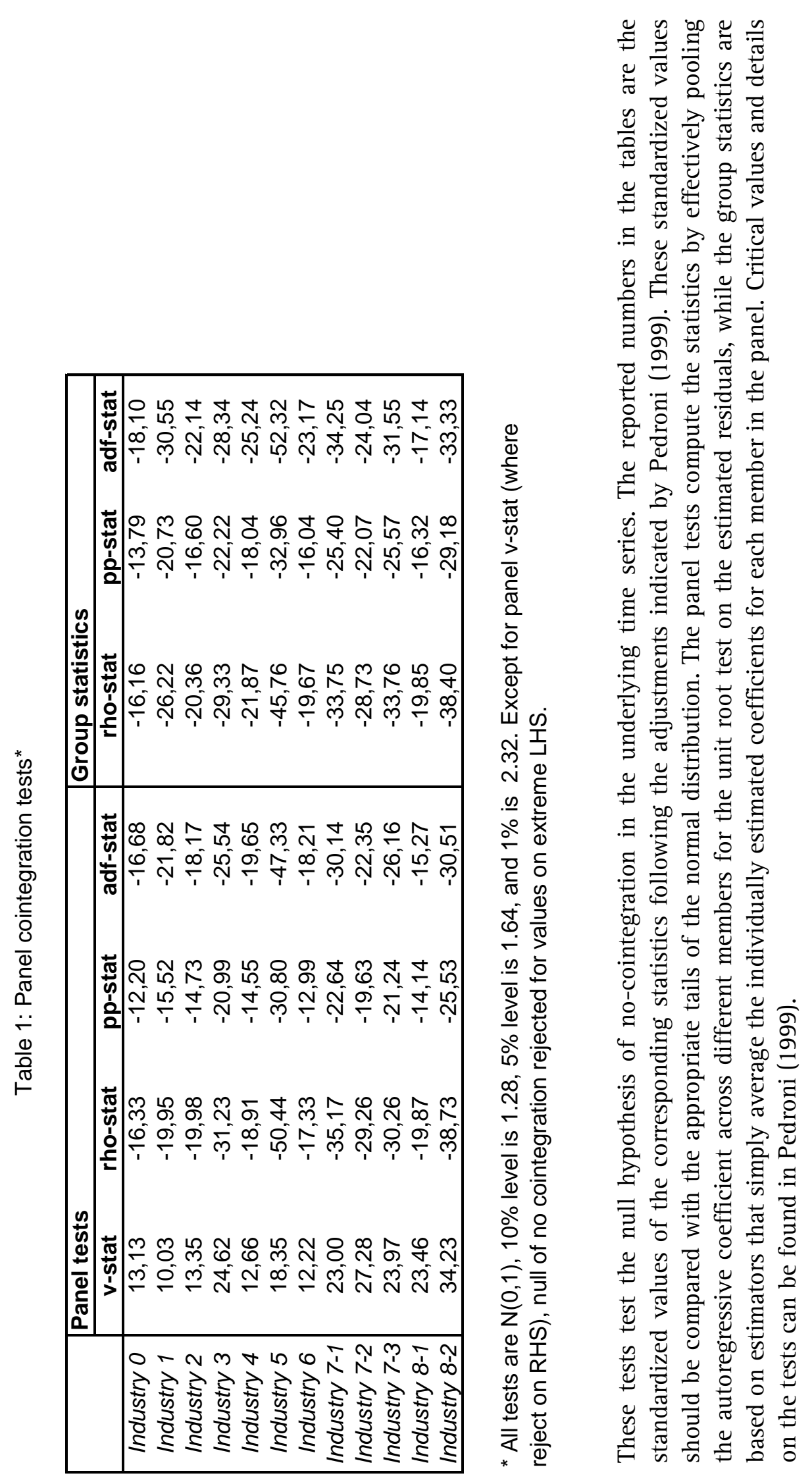


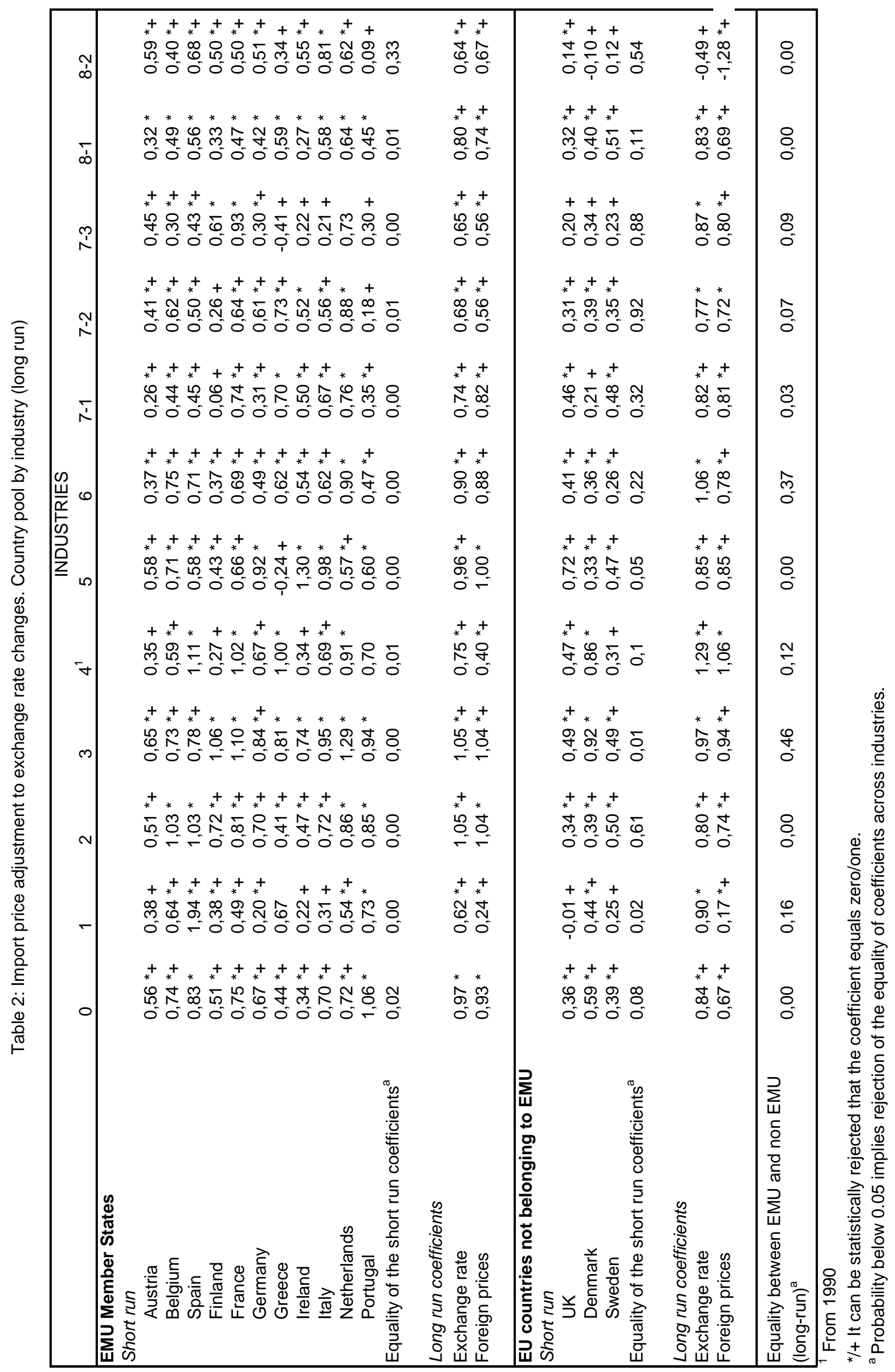




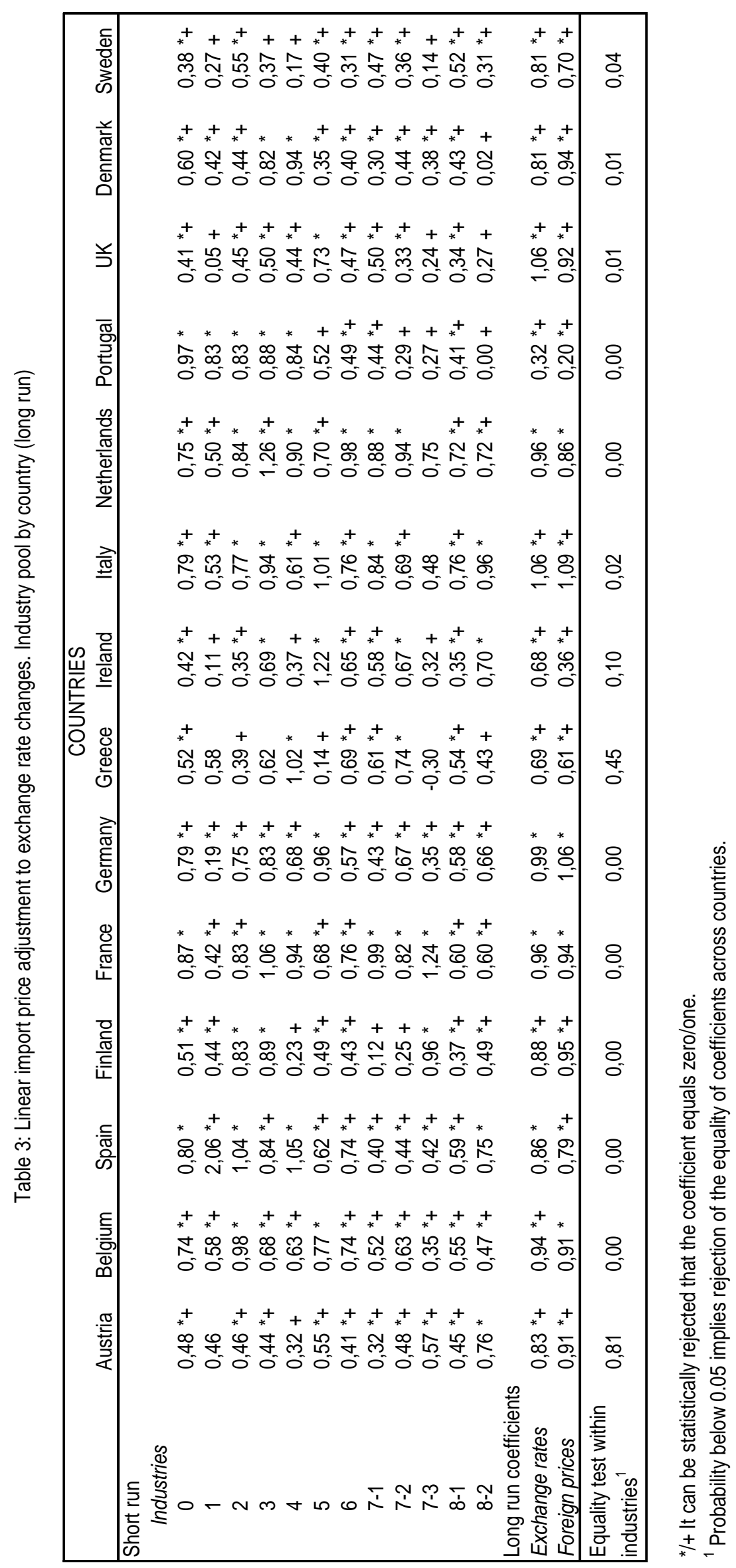




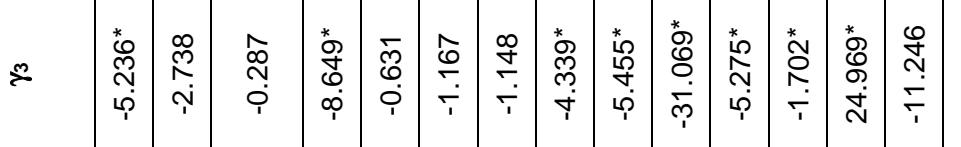

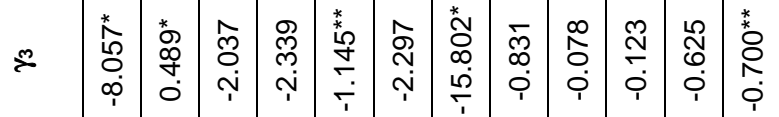

$\stackrel{+1}{+}$

$\overbrace{\substack{+ \\ \text { I }}}^{+}$

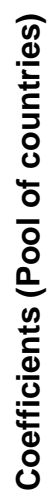

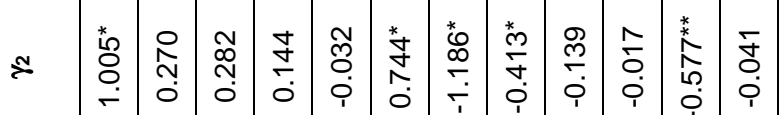




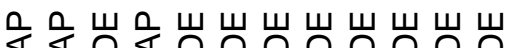

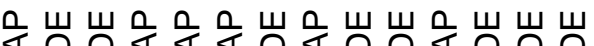

$\wedge \wedge \wedge \wedge \wedge \wedge \wedge \wedge \wedge \wedge$

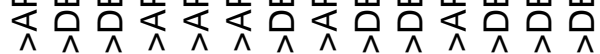

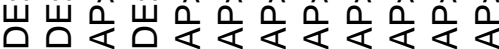

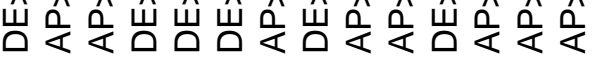

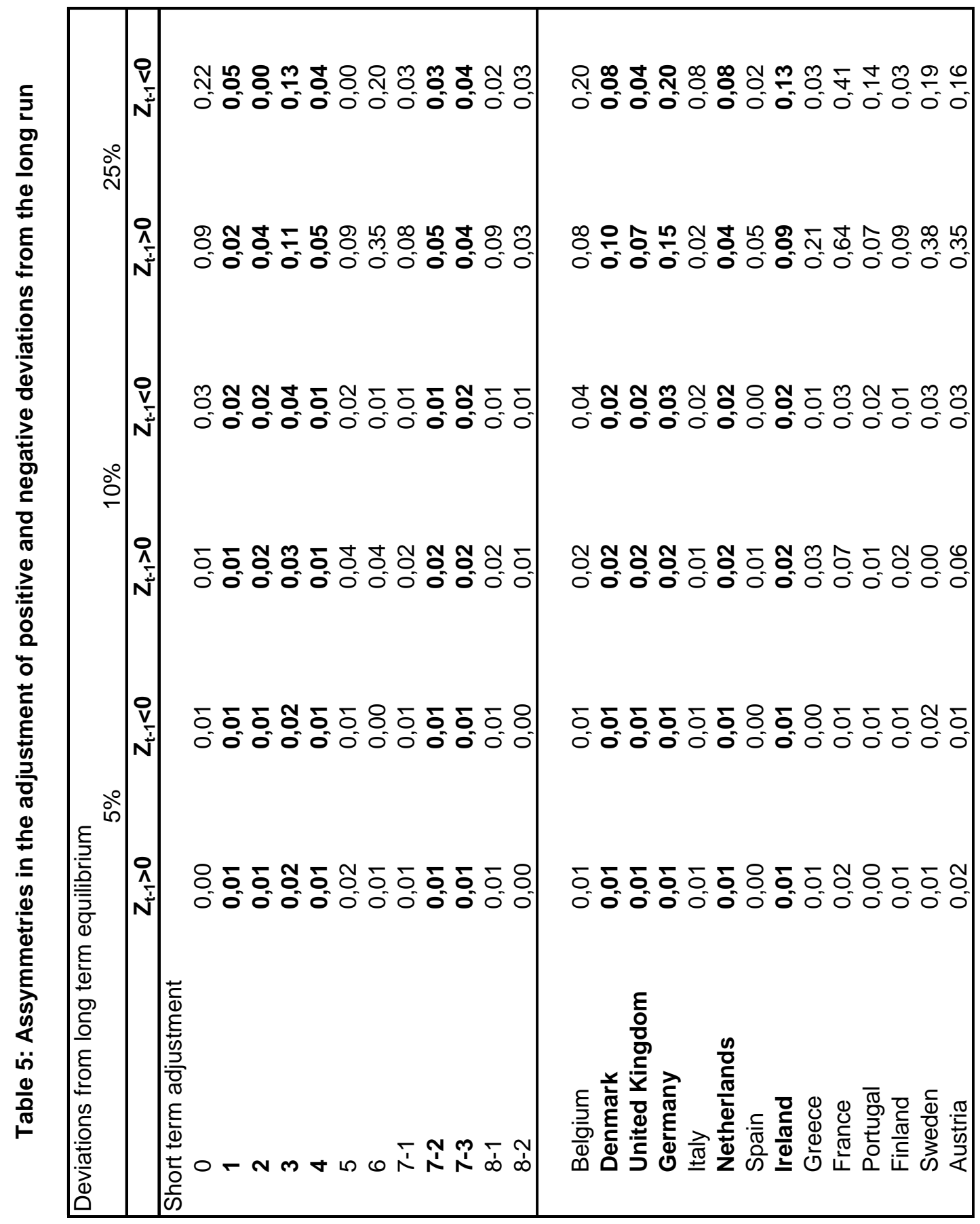

능 


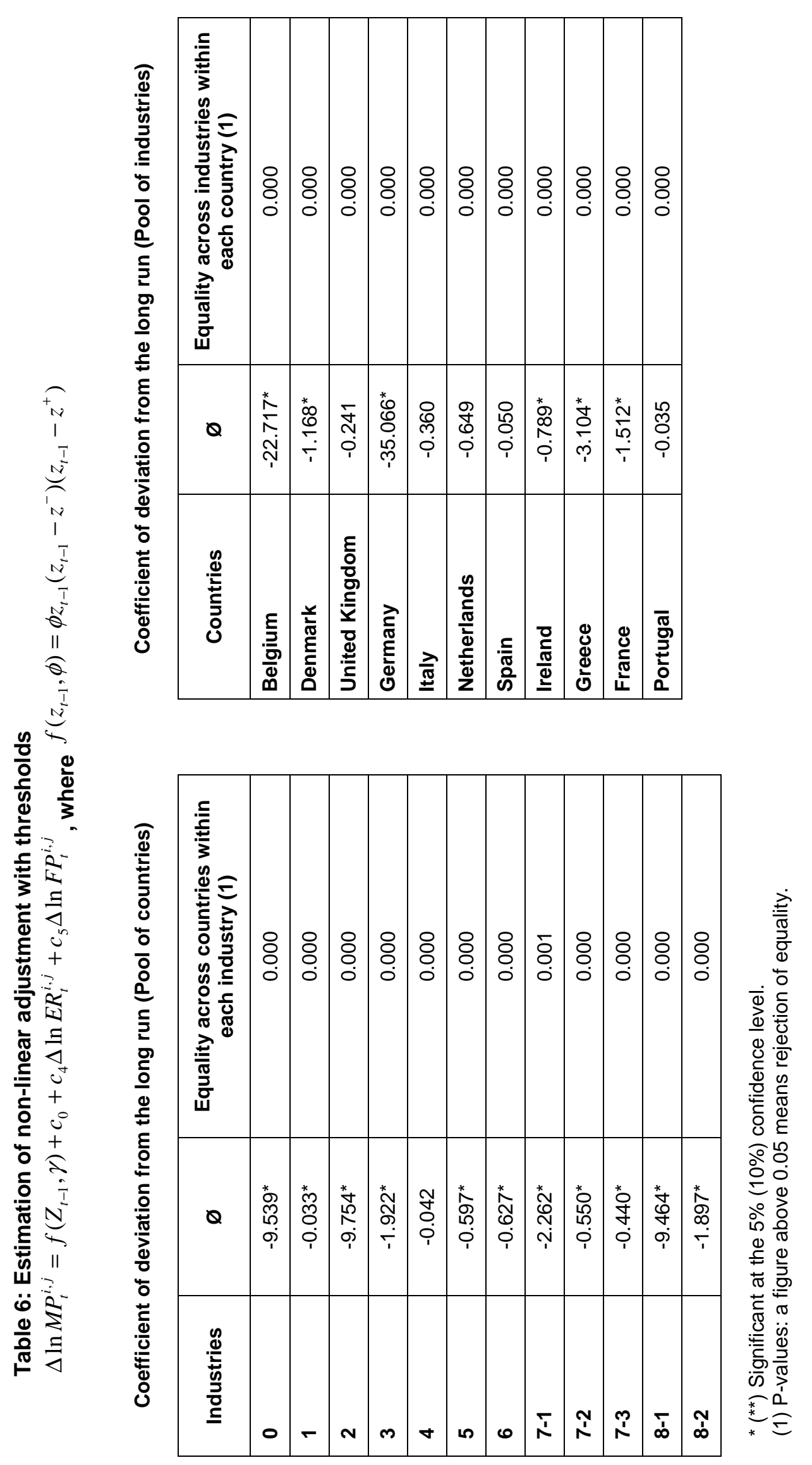




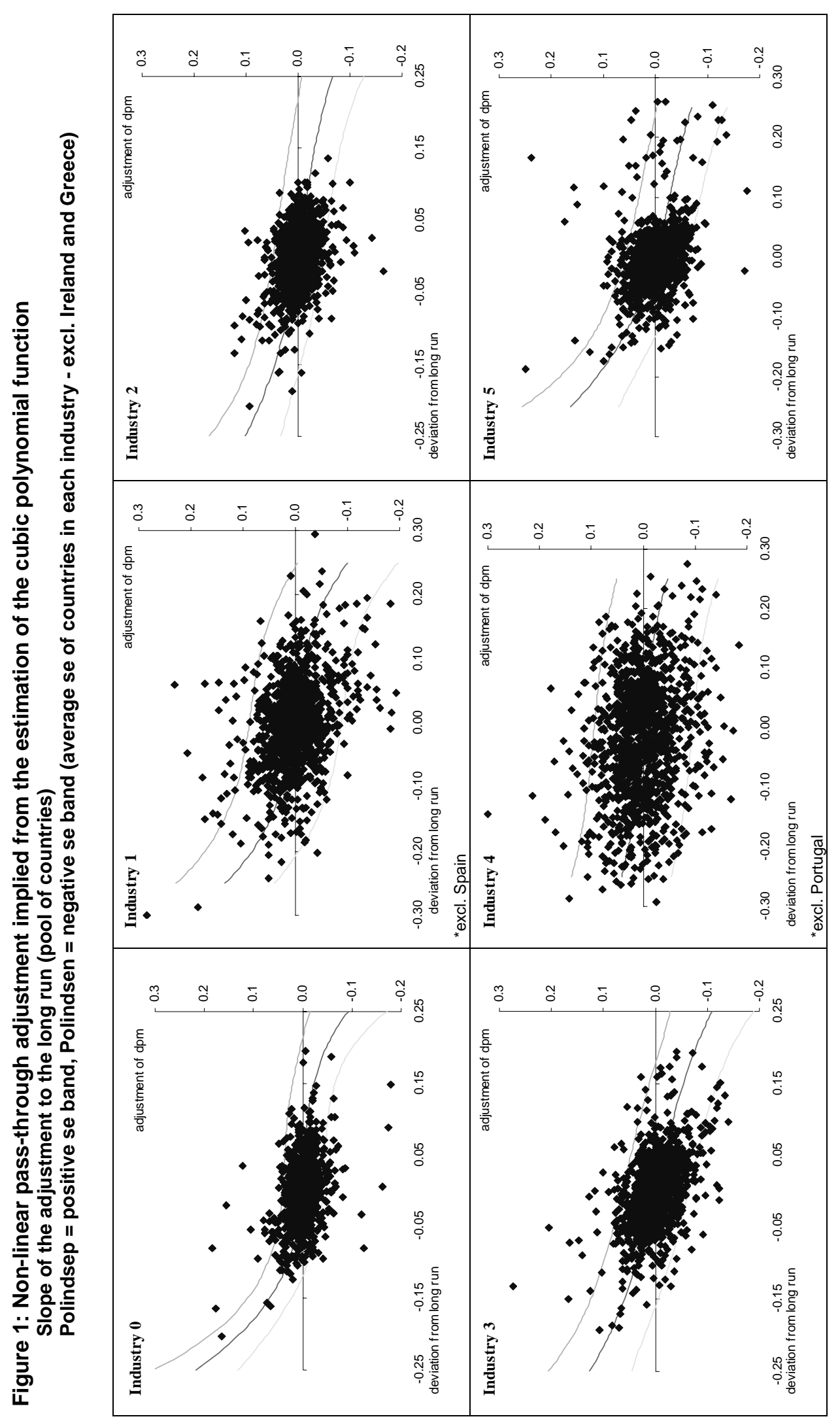




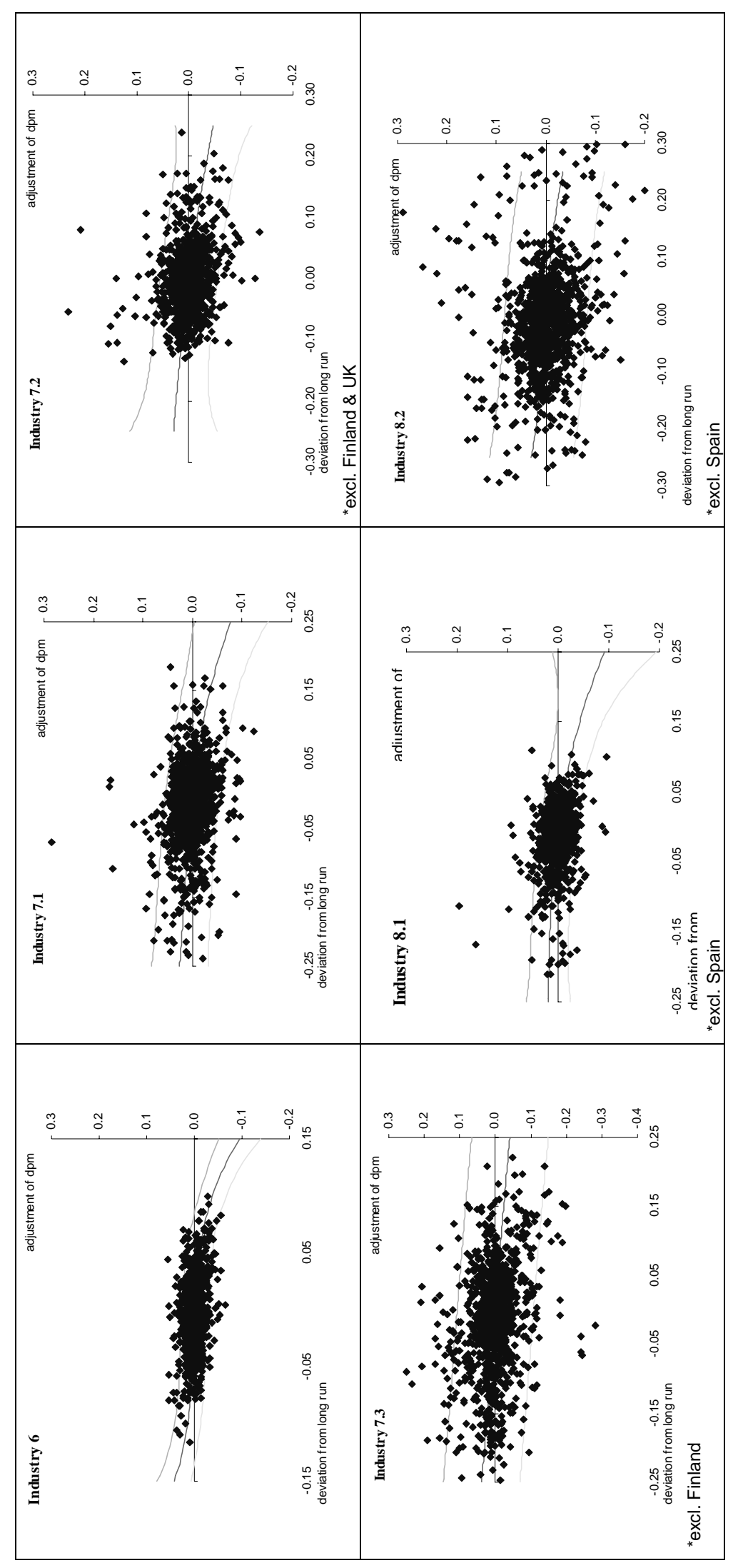




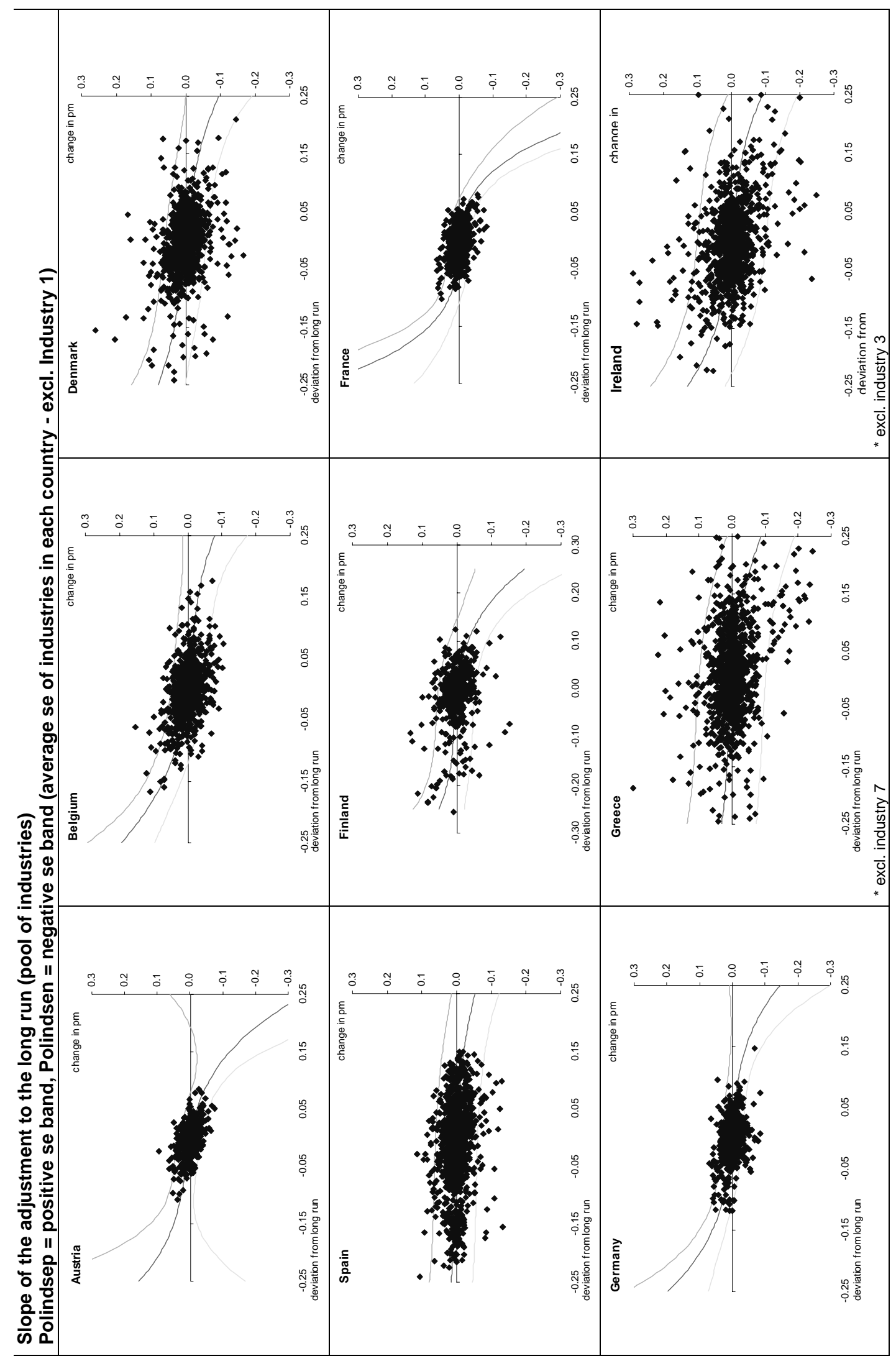




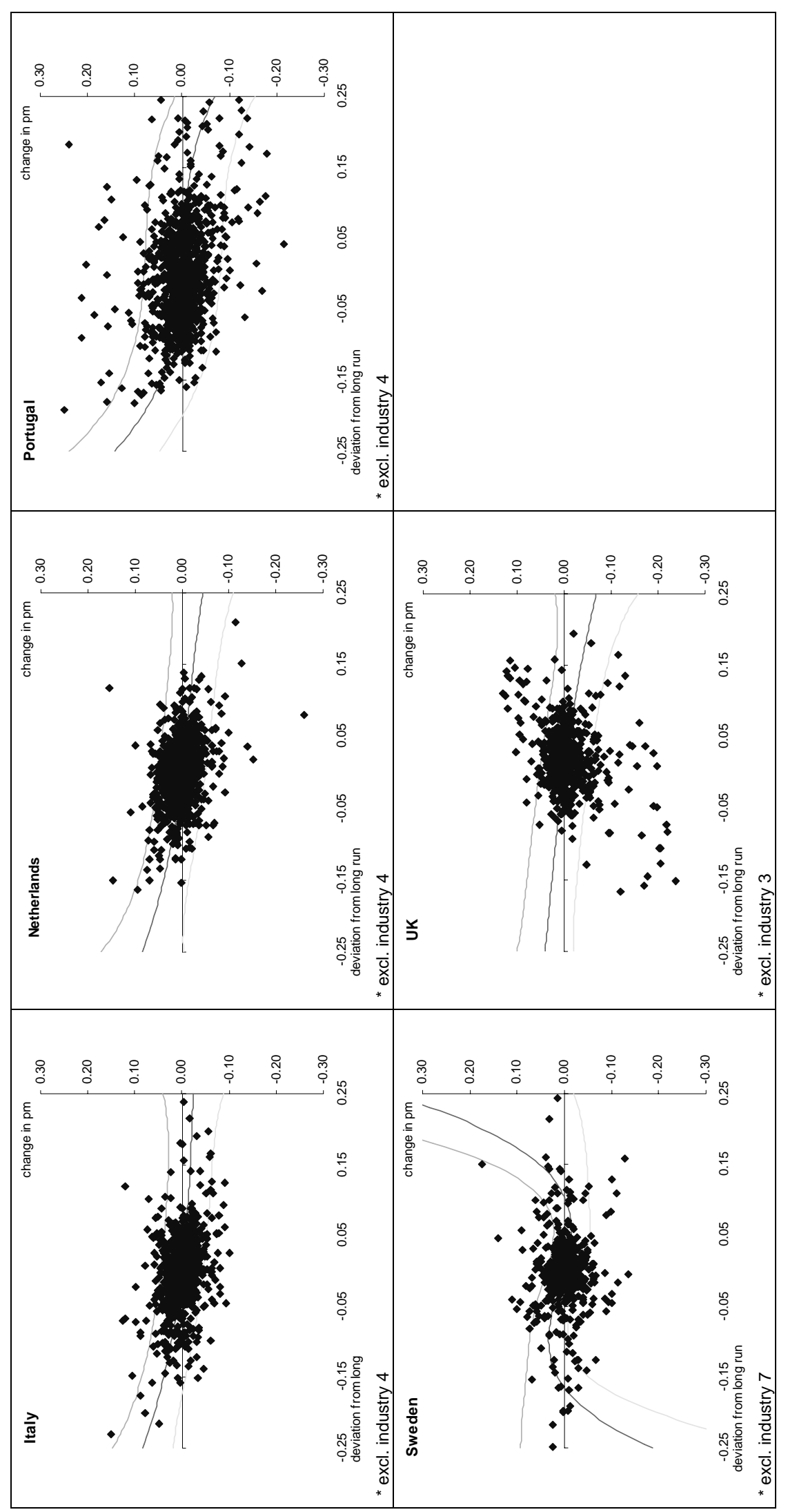




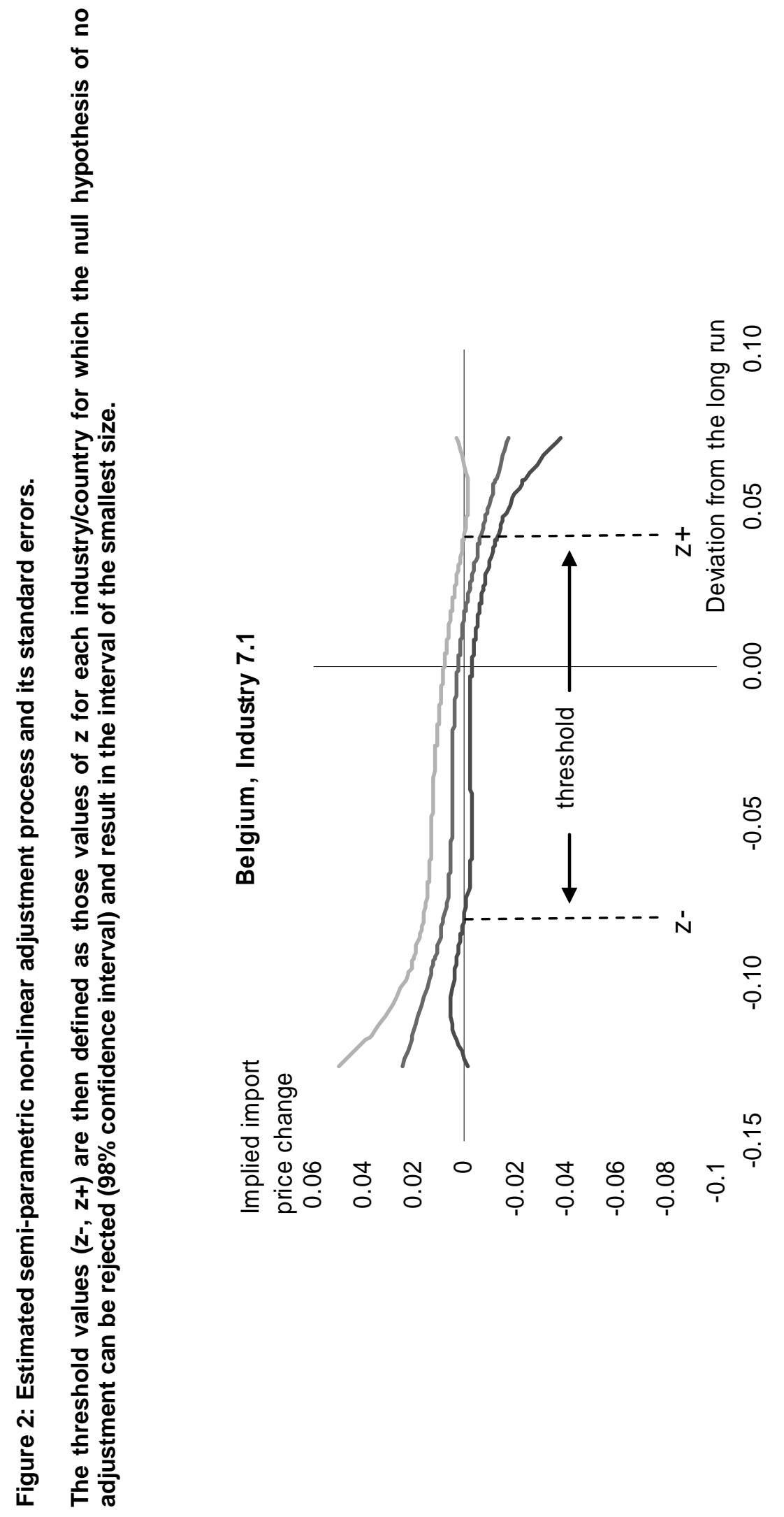




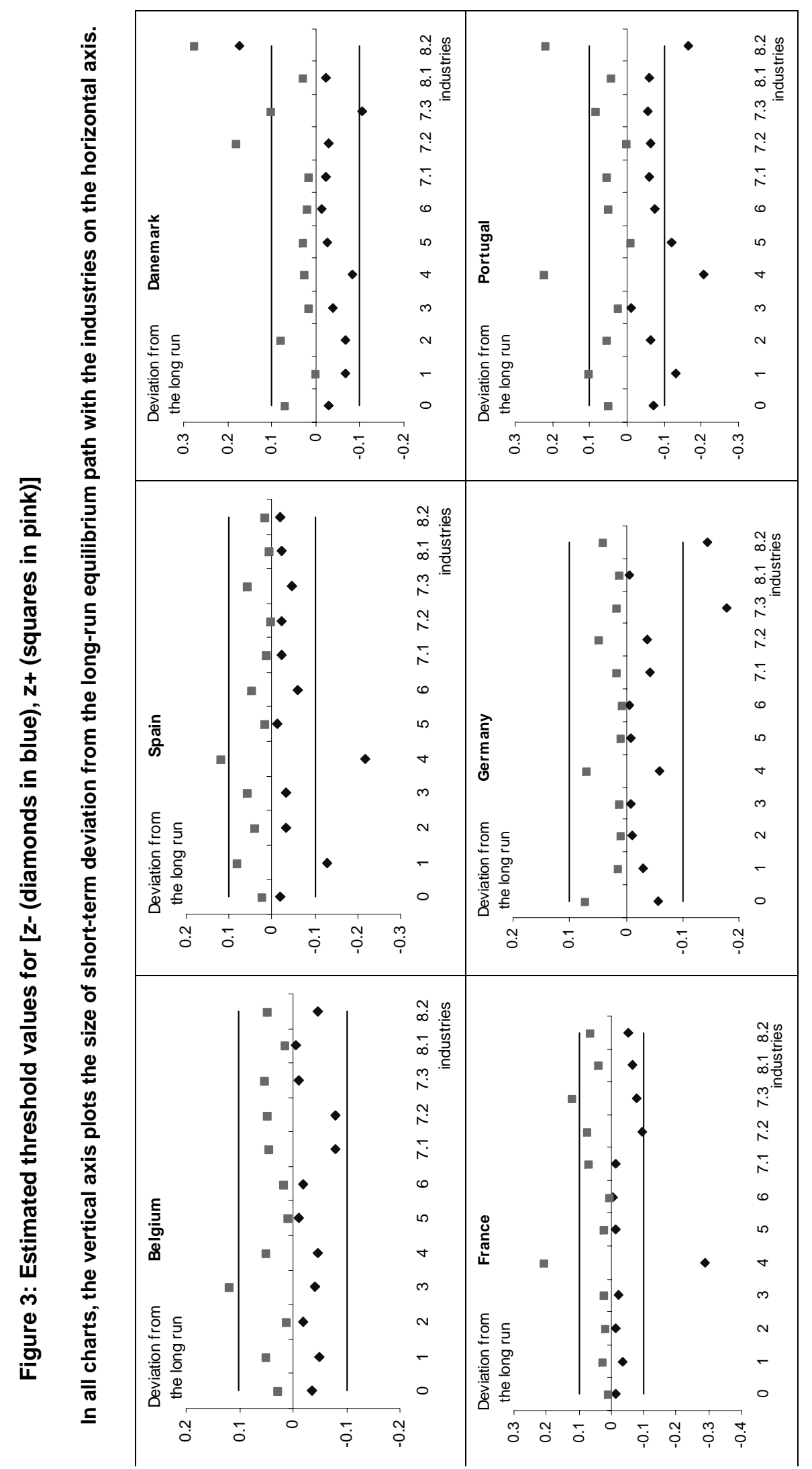




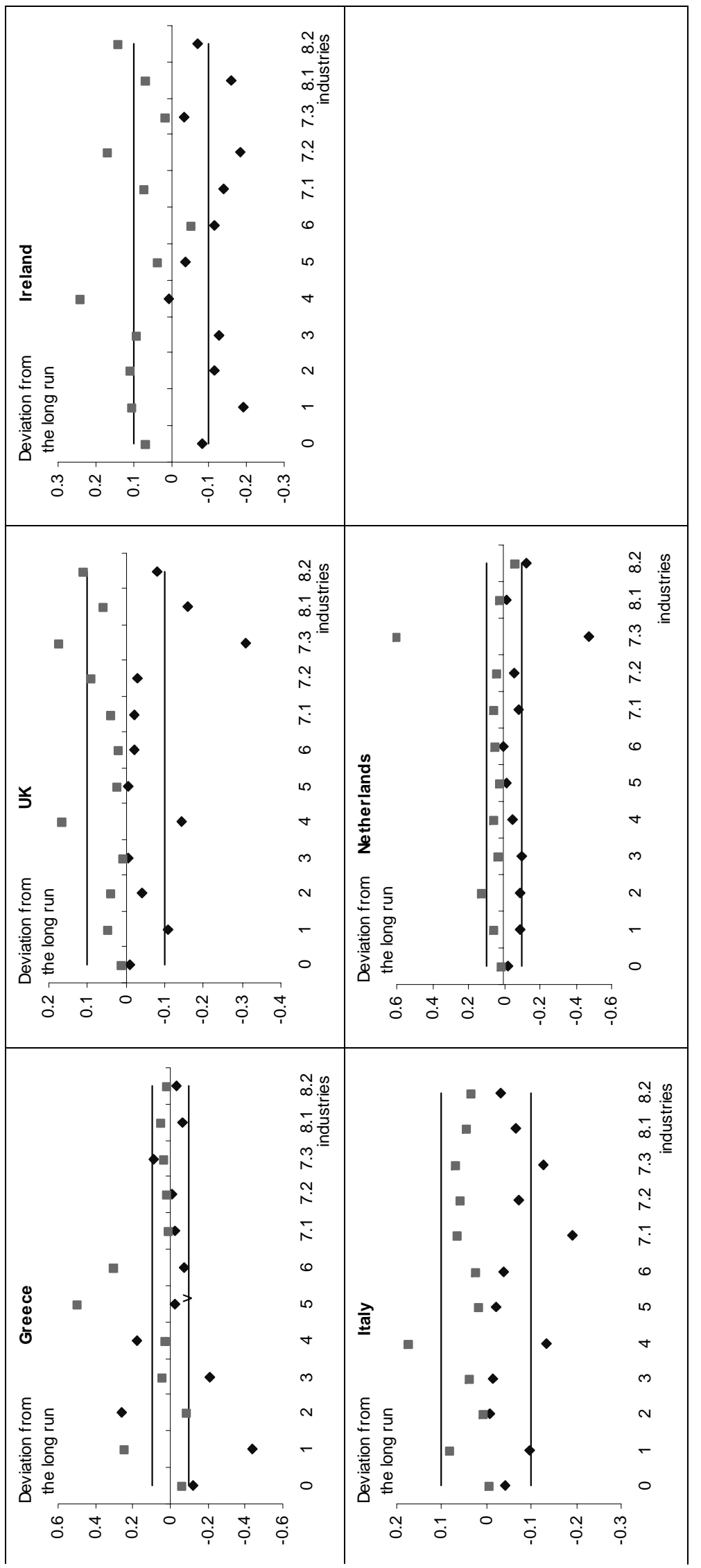

